\title{
Successful Function-Preserving Therapy for Chondroblastoma of the Temporal Bone Involving the Temporomandibular Joint
}

\author{
Junkichi Yokoyama ${ }^{a}$ Hitoshi Yoshimoto $^{c}$ Shin Ito ${ }^{a}$

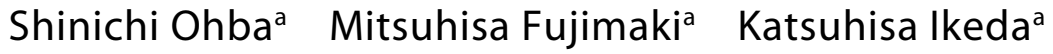 \\ Masaki Yazawa ${ }^{b}$ Nozomi Fujimiyad ${ }^{d}$ Makoto Hanagurie \\ aDepartment of Otolaryngology, Head and Neck Surgery, Juntendo University \\ School of Medicine, and bepartment of Plastic and Reconstructive Surgery, Keio \\ University School of Medicine, Tokyo, 'Department of Oral Maxillofacial Surgery, \\ Osaka Dental University, School of Dentistry, Osaka, 'Department of Outpatient \\ Therapy, Ishinomaki Municipal Hospital, Ishinomaki, and eDepartment of \\ Otolaryngology, Kyushu Rosai Hospital, Kitakyushu, Japan
}

\section{Key Words}

Chondroblastoma $\cdot$ Parotidectomy $\cdot$ Temporal bone $\cdot$ Temporomandibular joint $\cdot$ Trismus

\begin{abstract}
We present a case involving a late diagnosis of chondroblastoma of the temporal skull base involving the temporomandibular joint (TMJ). Following an initial misdiagnosis and unsuccessful treatment over a period of 5 years, the patient was referred to our department for further evaluation and possible surgical intervention for occlusal abnormalities, trismus, clicking of the TMJ, and hearing impairment. Based on preoperative immunochemical studies showing positive reaction of multinucleated giant cells for S-100 protein, the final diagnosis was chondroblastoma. The surgical approach postauricular incision and total parotidectomy, with complete removal of the temporal bone, including the TMJ via the extended middle fossa - was successful in preserving facial nerves and diminishing clinical manifestations. This study highlights a misdiagnosed case in an effort to underline the importance of medical examinations and accurate differential diagnosis in cases involving any tumor mass in the temporal bone.
\end{abstract}

\section{Introduction}

Chondroblastoma is a rare osseous tumor which accounts for less than $1 \%$ of all primary bone tumors, and affects the epiphyseal regions of the tubular bones, especially the ends of tibia, femur, and humerus [1]. Chondroblastoma localized in the head and 
neck region is uncommon but characteristically occurs in the temporal bone or the temporomandibular joint (TMJ) and results in various symptoms such as occlusal abnormalities, trismus, clicking of the TMJ, hearing impairments, dizziness, and otorrhea [2]. Malignant changes in chondroblastoma, although rare, have been observed after irradiation $[3,4]$. In order to avoid the inherent risk of malignant progression, radiation therapy should not be considered. However, chondroblastoma in the temporal bone has unusual histological features that make diagnosis difficult, and incomplete resection carries a high risk of recurrence $[5,6]$. Thus, it would seem advisable, provided the diagnosis is accurate, to attempt a complete surgical removal for the curative treatment of chondroblastoma.

Following 5 years of unsuccessful treatment, the patient was referred to our department presenting with chronic hearing impairments and subsequently progressive trismus. A tumor mass was present in the middle cranial fossa, including the TMJ and cochlea, in spite of earlier treatment regimens. By reporting this initially misdiagnosed case, the present study emphasizes the significance of the principles of a diagnosis. An accurate diagnosis was delayed because the original diagnosis relied on imaging analysis with neither careful magnetic resonance imaging (MRI)/computed tomography (CT) scanning analysis nor histopathologic examination. This less than thorough approach led not only to a delay of an accurate diagnosis and to unnecessary treatments, but also to a delay of suitable treatments for this rare chondroblastoma with malignant potential. This study presents methods which are helpful in diagnosing chondroblastoma, as well as suitable surgical procedures for maintaining postoperative functionality. In addition, this study highlights some of the problems posed by misdiagnosis.

\section{Case Report}

A 41-year-old male with TMJ disorder, initially diagnosed with otitis media, presented with a history of chronic (lasting more than 1 year) hearing loss on the right side. The patient underwent several attempts at antibiotic therapy and treatment for Eustachian tube blockage, but his symptoms were unresponsive to both systemic antibiotic agents and tubing therapy. His initial diagnosis of TMJ disorder was based on physical assessment of malocclusion and complaints of subsequently developed trismus. Therefore, the patient was administered 2 years of splint therapy. After these 2 years, endoscopic surgery, followed by several attempts to correct the malocclusion for the TMJ disorder, was implemented but resulted in no significant improvement in clinical manifestations. The patient was further assessed and a CT scan and pathologic examination showed the presence of a giant cell tumor in the temporal bone. No additional treatments were performed.

The patient harbored the primary disease and consulted us for persistent restriction of the mouth opening as well as hearing loss and dizziness, which he had noticed 5 years earlier. He reported worsening of dizziness and hearing impairment as time passed. Re-examination of the CT scan revealed that the tumor mass had progressively enlarged and had widely destroyed the middle cranial fossa in the temporal lobe (fig. 1). MRI displayed the presence of a poorly defined mass, with predominantly low signal and relatively high signal intensities, on T1- and T2-weighted sequences, respectively, involving the right middle cranial fossa and infratemporal fossa floor. The tumor mass invaded the right temporal lobe and destroyed the subzygomatic fossa (fig. 2). Hearing loss in the right ear, trismus, and paralysis in V2 had not been reported by the patient before visiting our department. No paralysis was observed in V1 and V3, nor in the facial, glossopharyngeal, or hypoglossal nerves. Hard, enlarged lymph nodes were palpable in the right cervical region. Re-examination of combined MRI/CT scanning indicated rapid enlargement and widespread invasion of the mass into the cranial bone, with enlarged lymph nodes in the cervical region, providing evidence for chondrosarcoma or chondroblastoma in the temporal bone (data not shown). Preoperative histopathologic studies of the biopsy specimens for S-100 protein (rabbit polyclonal antibody; Dako, Denmark) were performed on formalin-fixed, paraffin-embedded tissues, using an avidin-biotin-complex method as instructed by the manufacturer. Histopathologic findings 
showed extensive proliferation of multinucleated giant cells with circular nuclei showing a sheet-like structure, formation of a small quantity of acidophilic substrate in the tumor mass, large cystic areas, and the presence of hemorrhage and aneurismal bone cysts indicating secondary aneurism-like bone

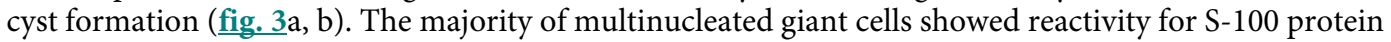
(fig. 3c). At this point, preoperative re-examinations of combined MRI/CT scanning and pathologic findings revealed the features of chondroblastoma.

A generous C-shaped postauricular incision was made through the skin and subcutaneous tissue, which was elevated to expose the underlying fascia, periosteum, and muscle. The incision was extended down to the cervical region to allow exposure of the sternocleidomastoid (SCM) muscle, the carotid artery, and the internal jugular vein. Neck dissection was performed ranging in scope from removal of level II and III nodes to possible radical neck dissection, and total parotidectomy was performed while leaving facial nerves intact (fig. $4 \mathrm{a}$ ). A radical mastoidectomy was performed to achieve complete exposure of the mastoid and tympanic segments of the facial nerve. The facial nerve was released to move easily without traumatic tension. All mucosa from the middle ear and drum was removed. The auditory tube was covered with muscles to help prevent infection through the nasopharynx. A pericranial flap was elevated to resect the temporalis muscle. A temporal craniotomy was performed. Subtotal resection of the temporal bone and skull base dissection with resection of TMJ using a zygomatic-extended middle fossa approach was carried out. The temporal lobe dura was resected about $30 \mathrm{~cm}^{2}$ together with part of the temporal lobe. The dura was reconstructed using fascia lata and covered with the pericranial flap and the temporalis muscle, and reconstruction using the SCM and the platysma muscle was performed to prevent infection and dysfunction (fig. $4 \mathrm{~b}$ ). Reconstruction of the facial tissue allowed the patient to open his mouth to the extent of $40 \mathrm{~mm}$ with no pain (fig. 5 ).

This study underlines an attempt to use conventional surgical procedures, with some modifications, for the treatment of chondroblastoma in order to prevent postoperative TMJ dysfunction, including malocclusion, trismus, and dysphagia, while preserving the masseter, the coronoid process, and the anterior part of the temporal muscle. These latter three retain the mandible to the anterior and maintain its stability. Reconstruction for facial tissues was carried out by inserting the SCM muscle flap into the infratemporal fossa. The SCM flap was then fixed to the resected end of the zygoma inside the mandible. This procedure prevented the mandible from transferring to the posterior. The soft tissues around the TMJ were removed.

Four and a half years after surgery, enhanced CT imaging showed no residual tumor. The patient had no clinical evidence of tumor recurrence during this period, nor of dizziness, with improvement of the occlusal abnormalities and trismus, indicating no postoperative dysfunction. The patient did not undergo postoperative irradiation since this is contraindicated with a diagnosis of chondroblastoma. In addition, the preservation of facial nerves resulted in recovery without neurological complications. Postoperative CT scans confirmed a total excision of the tumor in the temporal region.

\section{Discussion}

The present study underlines the importance of an accurate diagnosis especially for a mass in the temporal bone. Tumors such as chondroblastoma, which may originate as benign, may become malignant under inappropriate treatment. In fact, a combined radiotherapeutic-surgical approach may provoke neoplastic transformation in the residual tumor tissues of chondroblastoma $[4,5,7]$.

Following an inaccurate diagnosis, the patient in this study had been given various therapies for 5 years. The misdiagnosis was attributable to the difficulty of a differential diagnosis since the clinical manifestations can be indistinguishable from giant cell tumor, chondrosarcoma, aneurismal bone cyst, enchondroma, or chondromyxoid fibroma. Immediately before being referred to our department, the patient was misdiagnosed with giant cell tumor in the temporal region on the basis of CT scan/MRI plus pathology. Accordingly, no treatment was provided. Re-examination of CT/MRI indicated rapid enlargement and widely-spread invasion of a mass into the cranial bone, along with 


\begin{tabular}{|c|c|c|c|}
\hline $\begin{array}{c}\text { Case Reports in } \\
\text { Oncolous }\end{array}$ & $\begin{array}{l}\text { Case Rep Oncol 2011;4:74-81 } \\
\text { DOI: 10.1159/000324640 }\end{array}$ & $\begin{array}{l}\text { Published online: } \\
\text { February } 14,2011\end{array}$ & $\begin{array}{l}\text { O } 2011 \text { S. Karger AG, Basel } \\
\text { ISSN 1662-6575 } \\
\text { www.karger.com/cro }\end{array}$ \\
\hline
\end{tabular}

enlarged lymph nodes in the cervical region, showing a possibility of chondrosarcoma in the temporal bone. However, the widely- and rapidly-enlarged mass was found to have infiltrated the temporal lobes, and to have destroyed the middle cranial fossa. Lymph nodes in the temporal regions involving the squamosal temporal bone were enlarged. These findings provided evidence of malignant chondroblastoma in the temporal bone. The subsequent immunohistochemical examination of the lesion showed reactivity of the neoplastic protein mass for S-100 protein. The presence of S-100 protein in tumor cells differentiates chondroblastoma from giant cell tumor, chondrosarcoma, and aneurismal bone cysts, favoring the diagnosis of chondroblastoma [8-10]. The temporal lobes revealed extensive proliferation of multinucleated cells. The presence of associated aneurismal bone cysts is, while not absolute, a supplemental criteria for the diagnosis of chondroblastoma. These findings strongly suggest potentially malignant chondroblastoma.

Treatment of a chondroblastoma in the temporal bone requires total en bloc excision, curettage, and irradiation. Postoperative irradiation has been performed with the intention to reduce the risk of postoperative recurrence. However, it is not universally recommended due to malignant changes in chondroblastoma observed after irradiation. Radiation therapy should only be administered in cases of incomplete tumor removal. Conclusively, a total en bloc excision should be the first choice as a therapeutic approach for chondroblastoma in the temporal bone. In the case presented here, the tumor was located in a site that included important neurovascular components, which generally makes surgical resection impractical. Thus, accurate, early-stage diagnosis is a vital component to successful treatment. For patients with later-stage chondroblastoma, our modified surgical procedure is a valuable alternative.

\section{Disclosure Statement}

The authors have no conflicts of interest. 


\begin{tabular}{c|l|l|l}
$\begin{array}{c}\text { Case Reports in } \\
\text { Oncology }\end{array}$ & $\begin{array}{l}\text { Case Rep Oncol 2011;4:74-81 } \\
\text { DOI: 10.1159/000324640 }\end{array}$ & $\begin{array}{l}\text { Published online: } \\
\text { February 14, 2011 }\end{array}$ & $\begin{array}{l}\text { O 2011 S. Karger AG, Basel } \\
\text { ISSN 1662-6575 } \\
\text { www.karger.com/cro }\end{array}$ \\
\hline
\end{tabular}
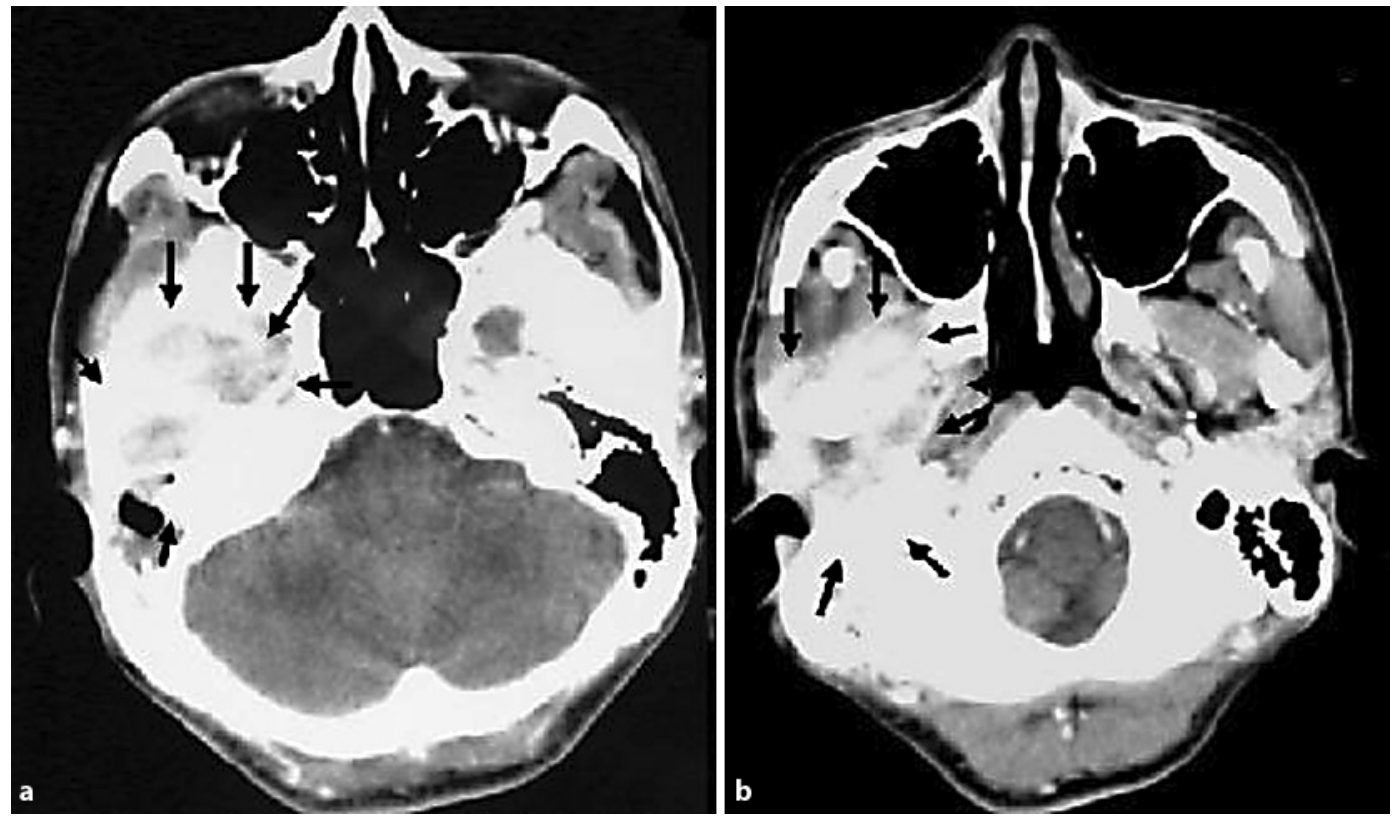

Fig. 1. Preoperative CT scans showing invasion of the tumor mass into the right temporal lobe. The arrows point out the tumor mass in the right intra-temporal lobe, invading the middle cranial fossa. a Sites indicating boney destruction in the middle cranial base. $\mathbf{b}$ Inferior sites responsible for the trismus.

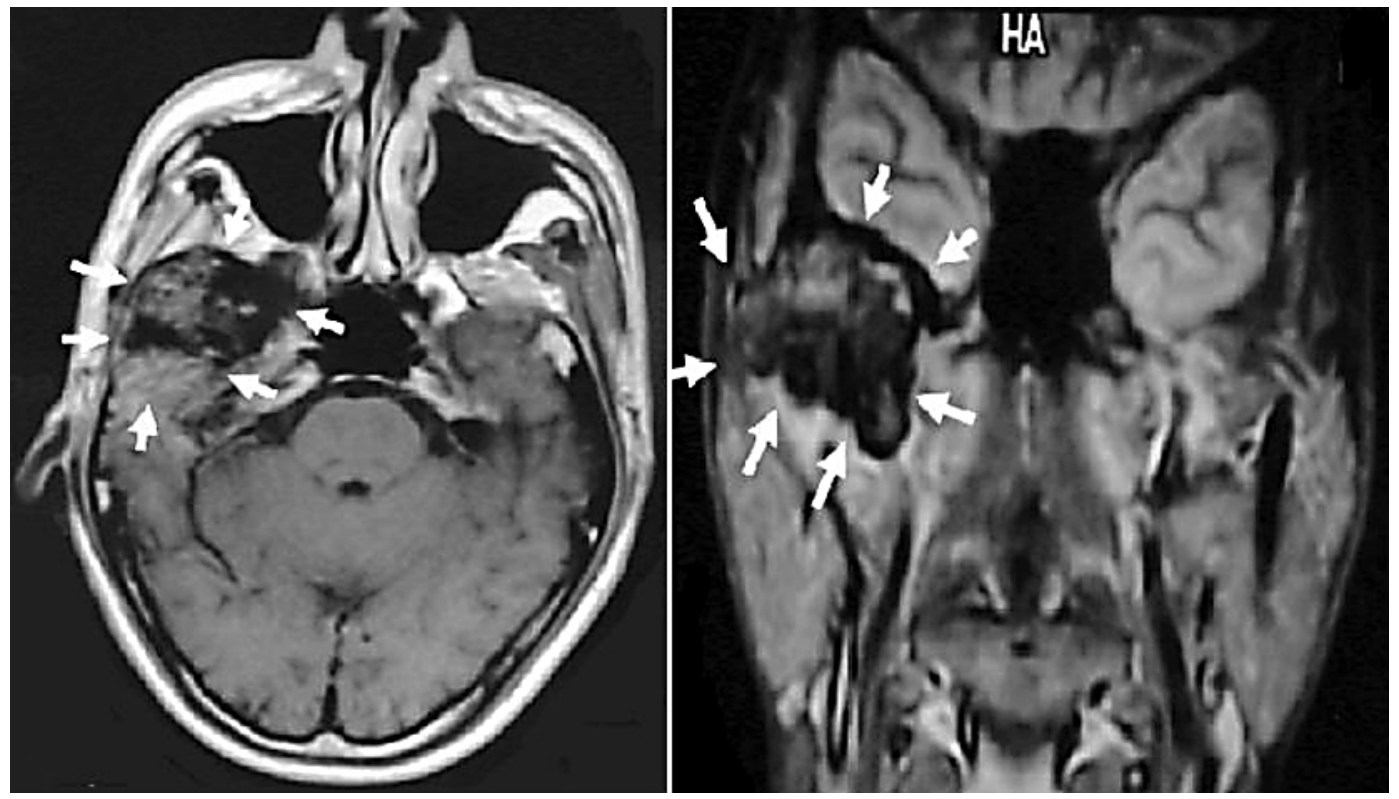

Fig. 2. Preoperative axial T1-/T2-weighted MR image showing invasion of the tumor mass into the right temporal lobe. The arrows point out the tumor mass in the right intra-temporal lobe, involving the right middle cranial and infratemporal fossae, and the presence of a poorly defined mass with low and relatively high signal on T1- (left) and T2- (right) weighted sequences, respectively. 


\begin{tabular}{c|l|l|l}
$\begin{array}{c}\text { Case Reports in } \\
\text { Oncology }\end{array}$ & $\begin{array}{l}\text { Case Rep Oncol 2011;4:74-81 } \\
\text { DOI: 10.1159/000324640 }\end{array}$ & $\begin{array}{l}\text { Published online: } \\
\text { February 14, 2011 }\end{array}$ & $\begin{array}{l}\text { O 2011 S. Karger AG, Basel } \\
\text { ISSN 1662-6575 } \\
\text { www.karger.com/cro }\end{array}$ \\
\hline
\end{tabular}

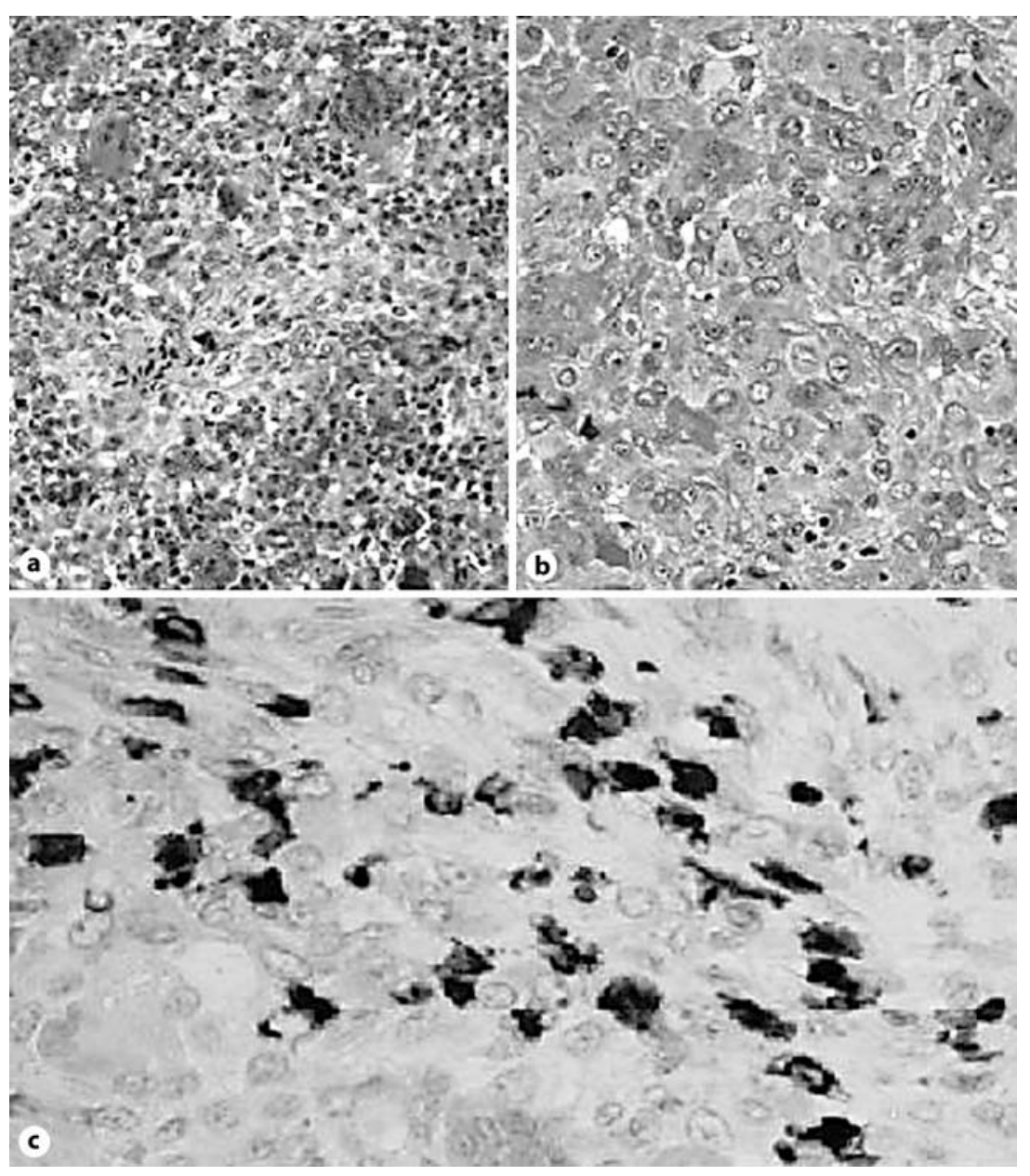

Fig. 3. Histopathologic cut confirming the diagnosis of chondroblastoma (HE, a $\times 100, \mathbf{b} \times 400)$. Microscopic examination revealed poorly circumscribed tumor with scattered multinucleated giant cells and multiple aneurism-like bone cysts with the presence of hemorrhage, representing secondary aneurismal bone cyst formation. Immunochemical staining indicates reactivity of the neoplastic cells for S-100 protein $(\mathbf{c})$. 


\begin{tabular}{c|l|l|l}
$\begin{array}{c}\text { Case Reports in } \\
\text { Oncology }\end{array}$ & $\begin{array}{l}\text { Case Rep Oncol 2011;4:74-81 } \\
\text { DOl: 10.1159/000324640 }\end{array}$ & $\begin{array}{l}\text { Published online: } \\
\text { February 14, 2011 }\end{array}$ & $\begin{array}{l}\text { O 2011 S. Karger AG, Basel } \\
\text { ISSN 1662-6575 } \\
\text { www.karger.com/cro }\end{array}$ \\
\hline
\end{tabular}

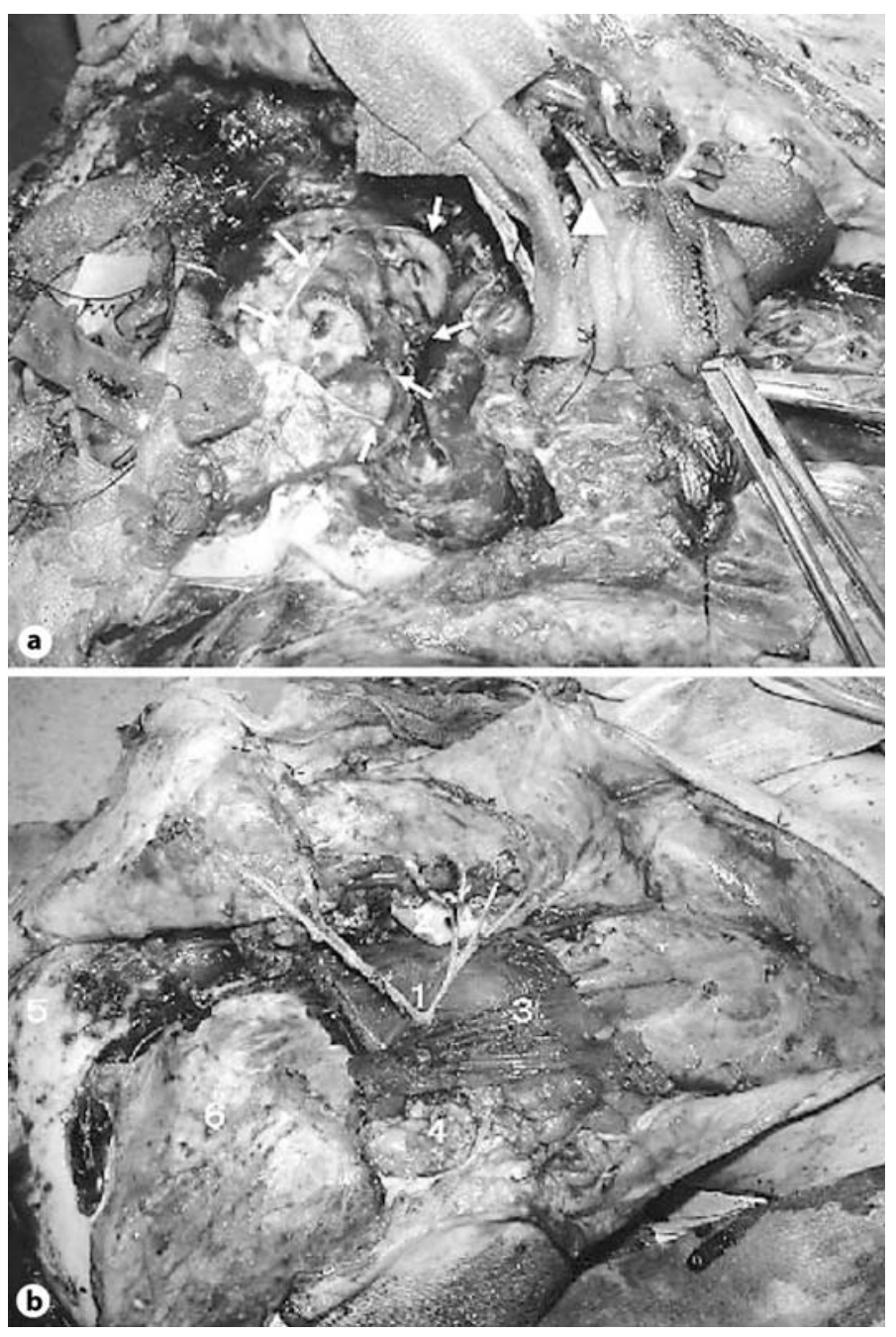

Fig. 4. Display of the technique for postauricular incision and total parotidectomy leaving facial nerves intact. Arrow head shows resected ramus mandible as well as resected dura. Facial nerves are preserved (a). Radical mastoidectomy and temporal craniotomy, preventing infection and dysfunction is shown (b). The detailed operative techniques are described in the text. $1=$ Facial nerve; $2=$ resected ramus mandible; 3 = SCM muscle reconstructed; $4=$ fat covering the tympanic cavity; $5=$ temporal bone; $6=$ pericranial flap. 


\begin{tabular}{|c|c|c|c|}
\hline $\begin{array}{r}\text { Case Reports in } \\
010010)\end{array}$ & $\begin{array}{l}\text { Case Rep Oncol 2011;4:74-81 } \\
\text { DOI: } 10.1159 / 000324640\end{array}$ & $\begin{array}{l}\text { Published online: } \\
\text { February 14, } 2011\end{array}$ & $\begin{array}{l}\text { (c) } 2011 \text { S. Karger AG, Basel } \\
\text { ISSN } 1662-6575 \\
\text { www.karger.com/cro }\end{array}$ \\
\hline
\end{tabular}

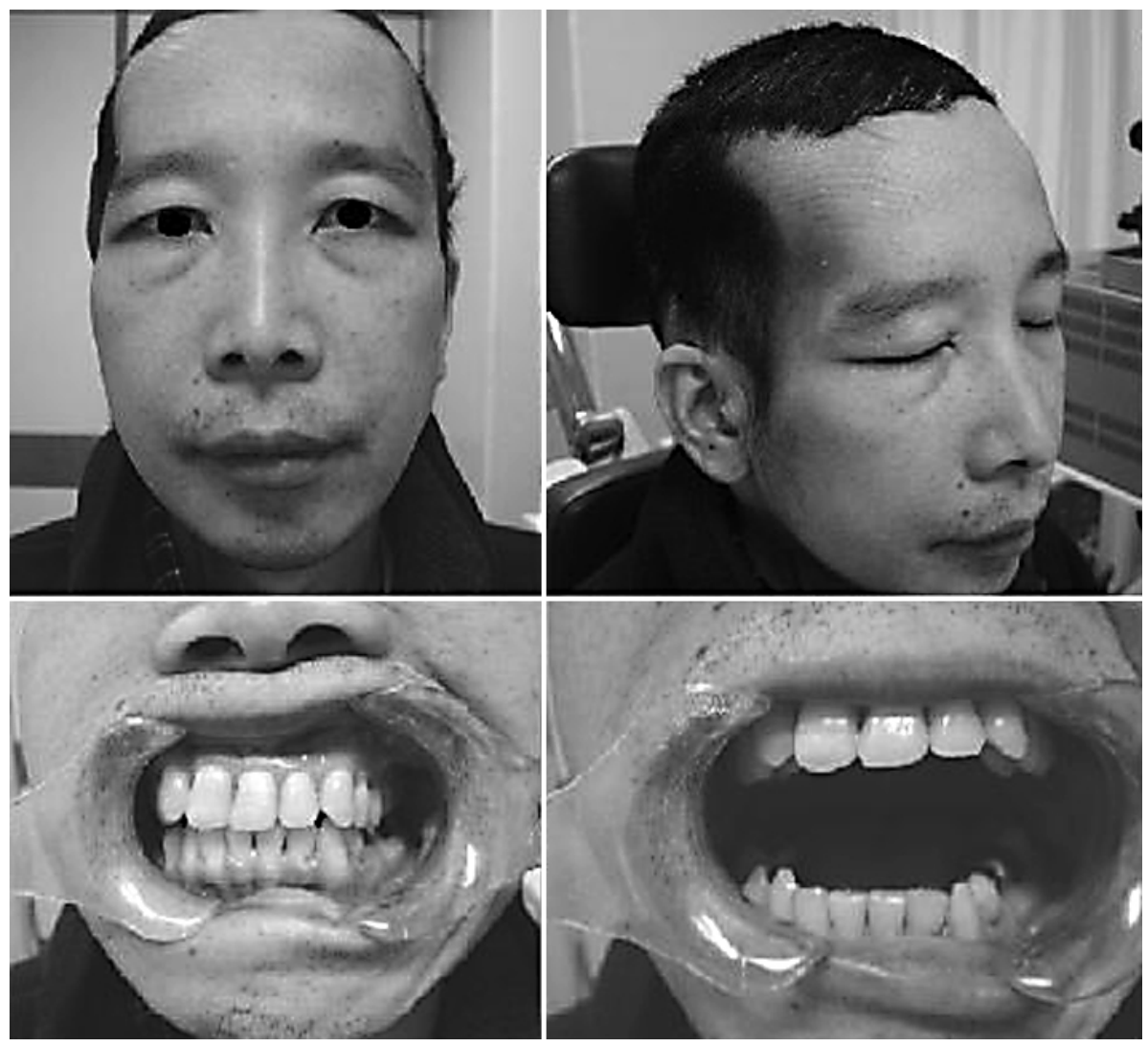

Fig. 5. Reconstruction of facial tissues using a modified surgical procedure. Facial palsy and surgical scar are not prominent after reconstructive surgery (upper two photos). Both upper and lower malocclusions of teeth are aligned (lower left photo) and chondroblastoma-induced trismus significantly improved postoperatively (lower right photo).

\section{References}

1 Dahlin DS, Ivins JC: Benign chondroblastoma. A study of 125 cases. Cancer 1972;30:401-413.

2 Denko JV, Krauel LH: Benign chondroblastoma of bone: an unusual localization in temporal bone. AMA Arch Path 1955;59:710-711.

-3 Hamer SG, Cody DT, Dahlin DC: Benign chondrosarcoma of the temporal bone. Otolaryngol Head Neck Surg 1979;87:229-236.

4 Steiner GC: Postradiation sarcoma of bone. Cancer 1965;18:603-612.

5 Flowers CH, Rodriguez J, Naseem M, Reyes MM, Verano AS: MR of benign chondroblastoma of the temporal bone. Am J Neuroradiol 1995;16:414-416.

6 Politi M, Consolo U, Panziera G, Capelli P, Bonetti F: Chondroblastoma of the temporal bone. J Craniomaxillofac Surg 1991;19:319-322.

7 Horn KL, Hankinson H, Nagel B, Erasmus M: Surgical management of chondroblastoma of the temporal bone. Otolaryngol Head Neck Surg 1990;102:264-269.

8 Bertoni F, Unni KK, Beabou JW, Harner SG, Dahlin DC: Chondroblastoma of the skull and facial bones. Am J Clin Pathol 1987;88:1-9.

9 Hong SM, Park YK, Roj Y: Chondroblastoma of the temporal bone: a clinicopathologic study of five cases. J Korean Med Sci 1979;14:559-564.

10 Watanabe N, Yoshida K, Shigemi H, Kurono Y, Mogi G: Temporal bone chondroblastoma. Otolaryngol Head Neck Surg 1999;121:327-330. 